BMJ Open Sport \& Exercise Medicine

\section{Association between hip joint impingement and lumbar disc disease in elite rowers}

To cite: Wedatilake T, Palmer A, Fernquest $\mathrm{S}$, et al. Association between hip joint impingement and lumbar disc disease in elite rowers. BMJ Open Sport \& Exercise Medicine 2021;7:e01063. doi:10.1136/ bmjsem-2021-001063

- Additional supplemental material is published online only. To view, please visit the journal online (http://dx.doi. org/10.1136/bmjsem-2021001063).

Accepted 1 October 2021

\section{Check for updates}

(c) Author(s) (or their employer(s)) 2021. Re-use permitted under CC BY-NC. No commercial re-use. See rights and permissions. Published by BMJ.

${ }^{1}$ Nuffield Department of Orthopaedics, Rheumatology, and Musculoskeletal Sciences, University of Oxford, Oxford, UK ${ }^{2}$ England and Wales Cricket Board, London, UK

${ }^{3}$ Royal National Orthopaedic Hospital Stanmore, Stanmore, UK

${ }^{4}$ British Rowing, London, UK ${ }^{5}$ English Institute of Sport, Bisham, UK

${ }^{6}$ Department of SEM, University of Nottingham School of Medicine, Nottingham, UK ${ }^{7}$ Imperial College London, London, UK

${ }^{8}$ Oxford University Hospitals NHS Foundation Trust, Oxford, UK

Correspondence to Dr Thamindu Wedatilake; thamindu@hotmail.com

\section{ABSTRACT}

Objectives Lumbar disc disease is a known cause of back pain. Increasingly it is thought that cam morphology of the hip may have a causal role in development of lumbar disc disease. The aim of this study was to describe the morphology of the hip and investigate the association of cam morphology with lumbar disc disease observed on MRI in elite rowers.

Methods Cross-sectional observational study of 20 elite rowers (12 male, 8 female, mean age 24.45 , SD 2.1). Assessment included clinical examination, questionnaires, 3T MRI scans of the hips and lumbar spine. Alpha angle of the hips and Pfirrmann score of lumbar discs were measured.

Results $85 \%$ of rowers had a cam morphology in at least one hip. Alpha angle was greatest at the 10 'clock position ((bone 70.9 (SD 16.9), cartilage 71.4 (16.3)). 95\% of the group were noted to have labral tears, but only $50 \%$ of the group had history of groin pain. $85 \%$ of rowers had at least one disc with a Pfirrmann score of 3 or more and $95 \%$ had a history of back pain. A positive correlation was observed between the alpha angle and radiological degenerative disc disease (correlation coefficient $=3.13, p=0.012$ ). A negative correlation was observed between hip joint internal rotation and radiological degenerative disc disease (correlation coefficient $=-2.60, p=0.018$ ).

Conclusions Rowers have a high prevalence of labral tears, cam morphology and lumbar disc disease. There is a possible association between cam morphology and radiological lumbar degenerative disc disease, however, further investigation is required.

\section{INTRODUCTION}

Rowing is a high-intensity sport associated with large volumes of training and high cumulative loading of the lumbar spine. ${ }^{1}$ It has been documented that the most frequent site of pain in rowers due to rowing is the lower back. ${ }^{1}$ In a study of a national rowing team, it was reported that $21.1 \%$ of all the illness and injuries were lumbar spine related. ${ }^{2}$ There are numerous causes for lumbar spine injuries and the role of MRI in diagnosing them remains controversial. ${ }^{3}$ However, MRI is highly sensitive for detecting degenerative

\section{Key messages}

What is already known

- Rowing is a high-intensity sport associated with large volumes of training and high cumulative loading of the lumbar spine.

- Frequent site of pain in rowers is the lower back.

- Rowers spend significant amounts of time in hip flexion during the rowing stroke.

What are the new findings?

- A high prevalence of asymptomatic labral tears and cam morphology exists among elite rowers.

- Cam morphology of the hip, resulting in reduced internal rotation, may be associated with degenerative lumbar disease.

- Clinicians assessing elite rowers with degenerative lumbar disk diseases may consider assessing the hip joint.

disc disease in the lumbar spine and furthermore is a validated method of measuring the degree of it. ${ }^{45}$

A high prevalence of femoroacetabular impingement (FAI) and labral injuries of the hip has also been reported in elite level rowers. ${ }^{6}$ FAI is a condition where the acetabular labrum and the soft tissues of the hip joint impinge due to asphericity of the femoral neck/head junction (cam lesion), or bony prominence of the acetabulum (pincer lesion). ${ }^{7}$ FAI increases the risk of labral pathology. ${ }^{7}$ Hip flexion in individuals with FAI can lead to chondro-labral damage at the point of impingement. ${ }^{9}$ Rowers spend significant amounts of time in hip flexion during the rowing stroke, which may predispose rowers to injuries of the labrum. The long-term consequences of having cam morphology and being a rower are unknown.

A proportion of rowers with FAI experience lower back pain. ${ }^{6}$ The possible relationship between FAI and lumbar spine pathology has been noted in a study of adolescent group of athletes in other sports. ${ }^{10}$ The reduced range 
of femoral movement and increased pelvic tilt seen during hip flexion in individuals with cam type FAI may put additional stress through the lumbar spine. ${ }^{9}$ This may a contributing factor to the high rates of lumbar injuries observed in rowers. ${ }^{11}$ However, there is limited research of the role that bone morphology of the hip plays on development of pathology in the spine in rowers.

The aims of this study were to determine the prevalence and characteristics of FAI in elite rowers hips and to examine the radiological relationship between hip joint FAI and radiological lumbar spine degenerative disc pathology.

\section{METHODS}

\section{Sample}

The study was a cross-sectional observational study of 20 elite-level rowers recruited from the Great Britain Rowing team aged 18-35. Recruitment was done following a presentation regarding the study to the rowing team, and volunteers from this group provided informed consent to participate in the study. As this was an exploratory study no sample size was calculated.

\section{Assessment}

Demographics, activity levels any history of back or hip pain and groin pain related to rowing, and leg dominance were collected using a questionnaire by a researcher (TW/AP). The following validated patient reported outcome measures collected were:

1. The Copenhagen Hip and Groin Outcome Score (HAGOS). ${ }^{12}$

2. Oswestry Disability Index. ${ }^{13}$

Individuals underwent clinical examination of the spine and hips by clinical research fellows and clinicians (TW/AP/LA). ${ }^{14} 15$ MRI was conducted of both hips and spine during the same visit.

\section{Imaging protocol}

MRI of both hips was performed on the same day of the assessment, using a 3T Siemens Skyra platform and torso coil (Siemans). The following morphological sequences were acquired: three-dimensional (3D) T1 volumetric interpolated breath-hold sequence sequence to image joint cartilage and bone, and proton density fat saturation in axial, coronal and sagittal planes to image the labrum. 3D multiplanar reconstructions were performed using OsiriX Software (V.6.0.2, Pixmeo). Radial images were acquired around the axis of the femoral neck at $30^{\circ}$ intervals. The coronal axis (12 o'clock position) was positioned parallel to the axis of the proximal femur diaphysis. Lumbar disc morphology was assessed using a T2-weighted sagittal plane image of the lumbar spine.

\section{Imaging measurements}

Hip

Cam morphology was quantified using the alpha angle for bone and cartilage (figure 1). Alpha angle was measured using custom-developed software on radial slices at 12
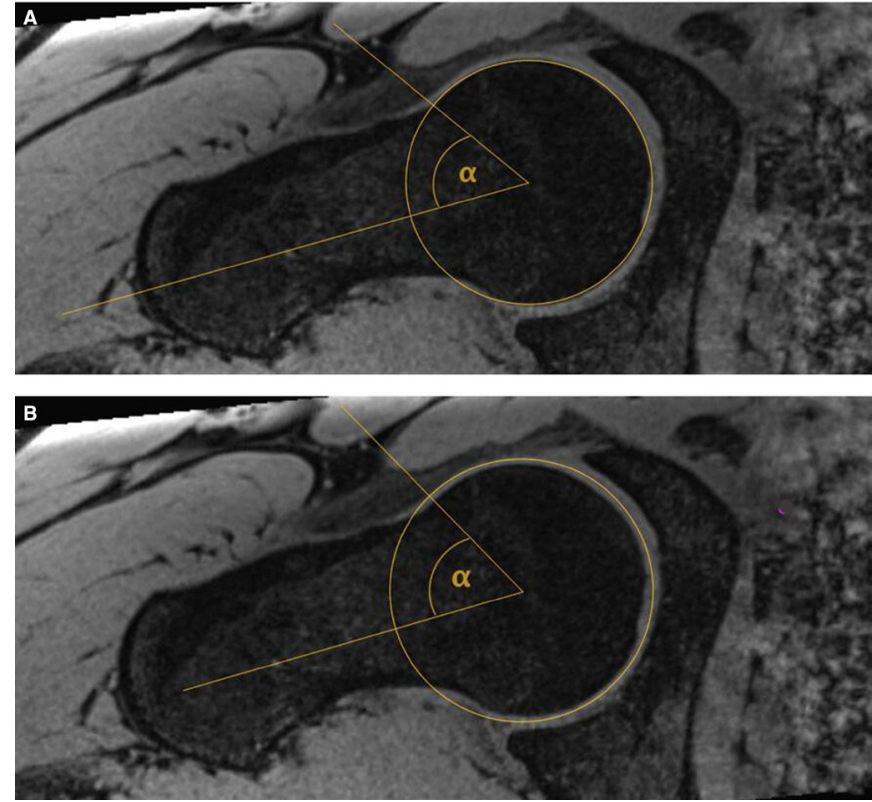

Figure 1 Alpha angle measurement for bone $(A)$ and cartilage (B) of the hip joint.

o'clock, 1 o'clock, 2 o'clock and 3 o'clock. ${ }^{16}$ The mean bone and cartilage alpha angle from 12 o'clock to to 3 o'clock were measured by an academic orthopaedic clinician (SF) blinded to participant information. ${ }^{9}$ Cam morphology was defined as an alpha angle of $60^{\circ}$ or more in at least two MRI planes of a hip. ${ }^{17} 18$ All MRIs were reviewed for labral pathology and articular cartilage disease by a consultant musculoskeletal radiologist blinded to other participant information.

\section{Lumbar spine}

Degenerative Disc disease was quantified using the Pfirrmann grading system. ${ }^{5}$ This is a validated standardised grading system to score lumbar spine degenerative disc disease and has been used in young adult spines. ${ }^{519} 20$ The Pfirrmann score was applied to the lumbar discs (L1/2, L2/3, L3/4, L4/5, L5/S1). A combined Pfirrmann score was used to encapsulate the effect on the spine as a whole, as disc disease can affect different discs in individuals and also multiple discs at the same time. ${ }^{19}$

Pfirrmann score of the lumbar spine was performed by clinical research fellow (TW) blinded to the hip radiological findings and participant information. All MRIs were reviewed and documented for disc herniations, neural impingement, high-intensity zone (HIZ) lesions, pars interarticularis defects/fractures and spondylolisthesis by a consultant musculoskeletal radiologist blinded to other participant information.

\section{Patient and public involvement}

First patient involvement was via a short presentation, by the researcher (TW) in the presence of team physician (AR), regarding the study aims and methods. All participants gave informed consent to participate in the study. The results of the investigations performed during the study were fedback, by the team physician (AR), to the 
individuals who wished to know their findings. Significance of findings, especially asymptomatic findings, were provided by team physician (AR).

\section{Statistical analysis}

Statistical calculations were performed using STATA V.14.1. Distribution of values was examined using histograms and kernel density plots. Parametic data were summarised using mean and SD, and comparison of means was undertaken using an independent two-tailed Student's t test. Linear regression modelling was adopted to assess relationship between variables. Statistical significance was set at $\mathrm{p}<0.05$.

\section{RESULTS}

\section{Participant demographics}

Twenty elite rowers (12 male and 8 female) with a mean age of 24.45 (SD 2.1) gave informed consent to enrol in the study. Forty hips and 20 lumbar spines were analysed in total. The group started rowing at a mean age of 14.5 (SD 2.8) years and had been rowing for mean time of 9.7 (SD 2.5) years. Fifty per cent of rowers said that they had hip/groin pain at some point in their career. There were no cases who had current back pain, however $95 \%$ had back pain in the past during their rowing career. The mean Oswestry Disability Index score was 4.7\% (SD 6.0) (online supplemental table 1).

\section{Hip morphology data}

Alpha angle was greatest at the 1 o'clock position both for bone (b) and cartilage (c) measurements (table 1). The mean alpha angle for males (69.5, SD 11.7) was larger compared with females (60.0, SD 8.2) $(\mathrm{p}=0.008)$. Eighty-five per cent of rowers had cam morphology in at least in one hip, $60 \%$ had bilateral involvement. $72.5 \%$ of all hips in the cohort had cam morphology. Ninetyfive per cent of the cohort had a labral tear noted on MRI. Only one hip had pathological articular cartilage changes (table 2).

\begin{tabular}{|c|c|c|c|}
\hline & & $\begin{array}{l}\text { Total mean alpha } \\
\text { angle for both } \\
\text { hips (SD) }\end{array}$ & $\begin{array}{l}\text { Total mean alpha angle } \\
\text { for maximum value of the } \\
\text { two hips (SD) }\end{array}$ \\
\hline \multirow[t]{2}{*}{12 o'clock } & Bone & $59.0(19.6)$ & $64.4(20.5)$ \\
\hline & Cartilage & $64.2(22.8)$ & 70.8 (22.8) \\
\hline \multirow[t]{2}{*}{1 o'clock } & Bone & 70.9 (16.9) & 75.7 (15.1) \\
\hline & Cartilage & $71.4(16.3)$ & 75.3 (14.6) \\
\hline \multirow[t]{2}{*}{2 o'clock } & Bone & $66.2(13.7)$ & 70.7 (12.2) \\
\hline & Cartilage & $65.9(13.6)$ & 70.6 (10.9) \\
\hline \multirow[t]{2}{*}{3 o'clock } & Bone & $55.0(14.6)$ & $60.3(15.6)$ \\
\hline & Cartilage & $56.9(13.6)$ & $62.3(14.1)$ \\
\hline
\end{tabular}

Table 2 Number of rowers with hip joint and lumbar spine clinical features

\begin{tabular}{llll}
\hline & \multicolumn{3}{l}{ No of rowers (\%) } \\
\cline { 2 - 4 } & Unilateral & Bilateral & Total \\
\hline Labral tear & $8(40)$ & $11(55)$ & $19(95)$ \\
\hline $\begin{array}{l}\text { Articular cartilage } \\
\text { changes }\end{array}$ & $1(5)$ & 0 & $1(5)$ \\
\hline $\begin{array}{l}\text { Pincer } \\
\text { Hip pain }\end{array}$ & $2(10)$ & $6(30)$ & $8(40)$ \\
\hline Disc herniation & $6(30)$ & $4(20)$ & $10(50)$ \\
Nerve root compression & 0 & Multiple levels & Total \\
\hline Spondylolisthesis & $3(15)$ & 0 & $6(30)$ \\
Spondylolysis & $3(15)$ & 0 & 0 \\
\hline HIZ lesion & $12(60)$ & $2(10)$ & $3(15)$ \\
\hline Back pain & & 0 & $3(15)$ \\
\hline
\end{tabular}

HIZ, high-intensity zone.

\section{Spine morphology data}

The most significant degenerative disc disease was seen at L5/S1 (table 3). It was noted that $85 \%$ of spines had at least one disc with a Pfirrmann score of 3 or more and $65 \%$ had at least one disc with a Pfirrmann score of 4 or more. Forty-five per cent of spines had two discs with a Pfirrmann score of 3 or more. HIZ lesions were common and seen in $70 \%$ rowers spines and nerve root compression was not seen in any of the spines (table 2).

\section{Hip morphology association with clinical tests}

Internal rotation (coefficient $=-0.96 p>0.001$ ), total rotation (coefficient $=-0.64 \mathrm{p}>0.001$ ), and hip joint extension (coefficient $=-1.61 \mathrm{p}=0.008$ ) of the hip showed significant negative correlation with the alpha angle. However, no correlation existed between the alpha angle and the FADIR (Flexion, Adduction, Internal Rotation) test (coefficient $=-0.56, \mathrm{p}=0.916)$ (table 4$)$.

Table 3 Degenerative disc disease of the lumbar spine as measured by Pfirrmann score

\section{No of rowers No of rowers} with Pfirrmann with Pfirrmann score of 3 or score of 4 or

\begin{tabular}{lccc} 
Disc level & $\begin{array}{l}\text { Pfirrmann } \\
\text { score median } \\
\text { (IQR) }\end{array}$ & $\begin{array}{l}\text { } \\
\text { more (in at least } \\
\text { one disc where } \\
\text { combined) (\%) }\end{array}$ & $\begin{array}{l}\text { more (in at least } \\
\text { one disc where } \\
\text { combined) (\%) }\end{array}$ \\
\hline L1/2 & $2(1-2)$ & 0 & 0 \\
\hline L2/3 & $1.5(1-2)$ & $3(15)$ & $1(5)$ \\
L3/4 & $1.5(1-2.5)$ & $5(25)$ & $3(15)$ \\
L4/5 & $2(1-3)$ & $7(35)$ & $3(15)$ \\
L5/S1 & $3.5(3-4)$ & $16(80)$ & $10(50)$ \\
\hline Combined & $8(6-8)$ & $17(85)$ & $13(65)$ \\
L3/4, L4/5, L5/ & & & \\
S1 & & &
\end{tabular}

S1

Combined all $10(9-11.25) \quad 17(85) \quad 13(65)$ discs 
Hip morphology association with degenerative lumbar disc disease

The alpha angle of bone (coefficient=2.85, $\mathrm{p}=0.031$ ) and cartilage (coefficient $=3.13, \mathrm{p}=0.012$ ) correlated with combined Pfirrmann scores. Internal rotation also correlated with combined Pfirrmann scores (correlation coefficient $=-2.60, \mathrm{p}=0.018)($ table 5$)$.

\section{DISCUSSION}

The aim of the study was to describe the morphology of the hip joint in rowers and investigate the association of cam morphology with lumbar disc disease. A high prevalence of asymptomatic labral tears, cam morphology and lumbar disc disease was observed in elite rowers. Moreover, reduced internal rotation of the hip secondary to cam morphology may be associated with degenerative lumbar disease in elite rowers.

\section{Hip joint morphology in rowers}

There are very few studies that describe the morphology and characteristics of a rowers hip joint. ${ }^{621}$ Our study is the first detailed review of a cohort of elite rowers hips. We found $85 \%$ of rowers have unilateral cam morphology, $60 \%$ have bilateral involvement and $72.5 \%$ of all hips met the criteria for cam morphology. The prevalence shown in this study was comparable to elite ice hockey players, ${ }^{22}$ football players ${ }^{23}$ and American football players. ${ }^{24}$ The mean alpha angle of the hip joint was at its greatest at 1 o'clock for both bone and cartilage. The mean alpha angle was comparable to angles seen in a footballers ${ }^{162325}$ elite ice hockey players ${ }^{22}$ but overall was higher compared with a general sporting population. ${ }^{26}$

MRI analysis revealed $95 \%$ of rowers in this cohort had at least one hip with a labral tear and $75 \%$ of all hips of the cohort had a labral tear. However, during their entire rowing career to date, only $50 \%$ of the cohort had experienced hip/groin pain in at least one hip and only $35 \%$ of all hips in the cohort had hip/groin pain. Similar to our study, other studies have shown that athletes are likely to have asymptomatic labral tears in $54 \%$ of hips. ${ }^{27}$ Only one rower having articular cartilage involvement is probably a reflection of a younger age group, where more advanced changes due to FAI has not developed as of yet.

The negative correlation between internal rotation, total rotation and hip extension and alpha angle of the hip joint is an important finding, as these are potentially simple bed side tests that can be performed to assess FAI. Especially the increasing alpha angle strongly correlated with reducing hip joint internal rotation, which consolidates findings of previous studies. ${ }^{16}$

Cam development is thought to be at its maximum at ages $12-14 .{ }^{16}$ The majority of our cohort did not start rowing until 14 years of age, hence the development of cam morphology likely preceded the introduction of rowing into their exercise regimen. 
Table 5 Relationship between alpha angle, clinical tests and lumbar disc disease as measured by Pfirrmann score

\begin{tabular}{|c|c|c|c|c|c|c|}
\hline & \multicolumn{3}{|c|}{ Combined Pfirrmann score for L3/4, L4/5, L5/S } & \multicolumn{3}{|c|}{ Combined Pfirrmann score for all discs } \\
\hline & Coefficient & $95 \% \mathrm{Cl}$ & $P$ value & Coefficient & $95 \% \mathrm{Cl}$ & $P$ value \\
\hline Alpha angle for bone at 1 o'clock & 3.65 & 0.13 to 7.16 & 0.043 & 2.93 & 0.12 to 5.74 & 0.042 \\
\hline Alpha angle for cartilage at 1 o'clock & 3.94 & 0.46 to 7.42 & 0.028 & 3.31 & 0.58 to 6.05 & 0.020 \\
\hline $\begin{array}{l}\text { Alpha angle for cartilage at } 1 \text { o'clock for maximum } \\
\text { value of the two hips }\end{array}$ & 3.77 & 0.79 to 6.75 & 0.016 & 3.13 & 0.79 to 5.48 & 0.012 \\
\hline Internal rotation & -3.14 & -5.81 to -0.48 & 0.023 & -2.60 & -4.71 to -0.49 & 0.018 \\
\hline External rotation & 0.73 & -1.16 to 2.61 & 0.427 & 0.59 & -0.92 to 2.10 & 0.425 \\
\hline Total rotation & -2.41 & -6.37 to 1.54 & 0.215 & -2.02 & -5.17 to 1.13 & 0.195 \\
\hline Flexion & 0.21 & -1.09 to 1.50 & 0.737 & 0.27 & -0.76 to 1.30 & 0.594 \\
\hline Extension & -0.60 & -1.86 to 0.66 & 0.332 & -0.65 & -1.63 to 0.34 & 0.186 \\
\hline
\end{tabular}

\section{Rowers lumbar spine}

It is well known that rowers experience episodes of lower back pain. ${ }^{28-30}$ The most common pathology driving this is possibly lumbar disc disease. ${ }^{31}$ In our cohort, almost all $(95 \%)$ rowers had back pain at sometime in their career. The average Oswestry Disability Index was $4.7 \%$, which suggests low disability within this cohort due to back pain. We found that radiological degenerative disc disease defined by Pfirrmann score was the most common disc pathology evident in our cohort. We found disc herniations (30\% of total spines) and nerve root impingement $(0 \%)$ a rarer finding, however, the limitation of having only a sagittal T2 image must be considered. Three rowers had bilateral spondylolysis and secondary spondylolisthesis. In all cases, spondylolisthesis was grade 1 changes. ${ }^{32}$ Spondylolysis was bilateral in each case and from T2-weighted images, there was no indication of these being active, however, we did not have STIR MRI images to be certain.

\section{Hip joint morphology associations with the lumbar spine}

Kinematic studies have identified increased lumbarpelvic flexion as a contributing factor to lumbar back pain as a consequence of increased loading in the lower lumbar spine. ${ }^{33-35}$ Anterior rotation of the pelvis on the hips is key to the rowing stroke as, in conjunction with hip flexion, it enables the individual to achieve the technical component known as the catch. ${ }^{36}$ In the presence of cam and/or pincer morphology, it is hypothesised that one of two mechanisms occur: repeated hyperflexion of the hip joint during the rowing stroke may predispose to the development of chondrolabral pathology. ${ }^{6}$ Alternatively, to avoid premature contact between the proximal femur and acetabulum, the individual may posteriorly rotate the pelvis, leading to hyperflexion and increased loading of the lumbar spine. ${ }^{36}$ The relationship between increasing lumbopelvic flexion and asymmetrical hip flexion has previously been reported. ${ }^{37}$

In our study, the highest mean alpha angle was noted at 1 o'clock. For this we felt that this is the most likely area of the head/neck junction of the femur to first make contact and impinge with the labrum/acetabular rim during a rowing stroke. We used this alpha angle to correlate with a combined Pfirrmann score for the whole spine. The combined score has been used in previous studies to capture the degenerative disc disease within whole of the lumbar spine. ${ }^{19}$ There was a correlation seen between the alpha angle at 1 o'clock and the combined Pfirrmann score. Degenerative disc disease is the most common at L3/4, L4/5 and L5/S1 accounting for $70 \%$ of disc disease, ${ }^{38}$ this was also the case in our cohort, and we found that a combined score for these discs again correlated with hip joint alpha angle. Furthermore internal rotation of the hip joint negatively correlated with the size of the alpha angle and also both combined Pfirrmann scores. These findings suggest that the hip morphology and reducing hip internal rotation may have an association with lumbar disc disease. This is a unique finding in a cohort of elite rowers.

More recently, it is recognised by senior clinicians working in elite rowing that hip morphology may play a part in the development of back pain in rowers. It is also possible that abnormal spinal movements and lower back pain could be the first signs of coexisting hip joint impingement in this population. Our study is the first study to show this radiological association.

\section{Impact on clinical practice and wider population}

Our findings suggest that FAI and lumbar disc pathology are likely linked. The role of FAI in the development of lumbar spine pathology is largely unknown. We propose that when an elite athlete presents with back pain they should have their hip, pelvis and lumbar spine assessed with a focus on potentially adverse effects of FAI on lumbopelvic movements.

The negative correlation between hip joint internal rotation, and disc degeneration is a novel finding. Such a finding may give the clinician a simple bedside test to screen at risk populations.

From previous studies, we know that hip joint FAI changes are prevalent in the general population. ${ }^{39}$ Furthermore, back pain due to lumbar disc disease is one 
of the most common musculoskeletal problems in the general population. ${ }^{40}$ This certainly raises the possibility that FAI morphology plays a significant part in causing degenerative lumbar disc issues than earlier thought. This is the first such study that has looked at this, and next stages from this exploratory study would be to look at a larger cohort of subjects.

\section{Limitations}

The main limitation in this study is its sample size. We must stress that this is an exploratory study and would make way for a larger study looking at this association further. We appreciate that most lumbar degenerative disk disease are asymptomatic. ${ }^{41}$ However, in this exploratory study, it was aimed to show that there was merely a radiological correlation between FAI and a measurable radiological pathology (degenerative disk disease). Furthermore as $95 \%$ of our cohort had back pain at some point in their life it was not possible to draw conclusions regarding the associations between back pain and hip morphology.

To examine the lumbar spine, we only used one MRI sequence. While this was sufficient to grade degenerative disc disease using the Pfirrmann score, it was difficult to review pars defects, subtle neural compressions and modic changes in detail. Further limitations apply to using the alpha angle as a morphological measure. There exists no universally agreed diagnostic threshold for cam morphology and a quantitative value for pathological change in alpha angle is unknown. ${ }^{42}$

\section{CONCLUSIONS}

Our study shows that elite rowers have a high prevalence of asymptomatic labral tears, cam morphology and radiological lumbar degenerative disc disease. An increasing size of a cam morphology strongly correlated with the degree of radiological lumbar degenerative disc disease. As cam morphology is likely to precede the development of lumbar pathology they may be closely linked. Further study is required to determine if managing FAI can prevent lumbar pathology in rowers.

Contributors TW: Guarantor, design of the work, acquisition, analysis and interpretation of data, writing of manuscript. AP: design of the work, the acquisition, analysis and interpretation of data, SF: design of the work, the acquisition and analysis of data, critical revision, AR: design of the work, acquisition of data. LA: design of the work, the acquisition of data. SK: analysis and interpretation of data. AM: design of the work, critical revision. JT: analysis and interpretation of data. JN: design of the work, critical revision. SG-J: design of the work, critical revision.

Funding Arthritis Research Centre of Excellence for Sport, Exercise and Osteoarthritis (vs Arthritis Centre): Pump Priming Grant. Faculty of Sport and Exercise medicine and GE Research Fellowship.

Competing interests None declared.

Patient and public involvement Patients and/or the public were involved in the design, or conduct, or reporting, or dissemination plans of this research. Refer to the Methods section for further details.

Patient consent for publication Not applicable.

Ethics approval Oxford University Medical Sciences Inter-Divisional Research Ethics Committee (R48611/RE001).
Provenance and peer review Not commissioned; externally peer reviewed.

Data availability statement The data are not available given the small sample size and public profile of the athletes in the study.

Supplemental material This content has been supplied by the author(s). It has not been vetted by BMJ Publishing Group Limited (BMJ) and may not have been peer-reviewed. Any opinions or recommendations discussed are solely those of the author(s) and are not endorsed by BMJ. BMJ disclaims all liability and responsibility arising from any reliance placed on the content. Where the content includes any translated material, BMJ does not warrant the accuracy and reliability of the translations (including but not limited to local regulations, clinical guidelines, terminology, drug names and drug dosages), and is not responsible for any error and/or omissions arising from translation and adaptation or otherwise.

Open access This is an open access article distributed in accordance with the Creative Commons Attribution Non Commercial (CC BY-NC 4.0) license, which permits others to distribute, remix, adapt, build upon this work non-commercially, and license their derivative works on different terms, provided the original work is properly cited, appropriate credit is given, any changes made indicated, and the use is non-commercial. See: http://creativecommons.org/licenses/by-nc/4.0/.

\section{ORCID iD}

Thamindu Wedatilake http://orcid.org/0000-0002-2160-7739

\section{REFERENCES}

1 Wilson F, Thornton JS, Wilkie K, et al. 2021 consensus statement for preventing and managing low back pain in elite and subelite adult rowers. Br J Sports Med 2021;55:893-9.

2 Trease L, Wilkie K, Lovell G, et al. Epidemiology of injury and illness in 153 Australian international-level rowers over eight international seasons. Br J Sports Med 2020;54:1288-93.

3 Wassenaar M, van Rijn RM, van Tulder MW, et al. Magnetic resonance imaging for diagnosing lumbar spinal pathology in adult patients with low back pain or sciatica: a diagnostic systematic review. Eur Spine J 2012;21:220-7.

4 Rao D, Scuderi G, Scuderi C, et al. The use of imaging in management of patients with low back pain. J Clin Imaging Sci 2018;8:30.

5 Pfirrmann CW, Metzdorf A, Zanetti M, et al. Magnetic resonance classification of lumbar intervertebral disc degeneration. Spine 2001;26:1873-8.

6 Boykin RE, McFeely ED, Ackerman KE, et al. Labral injuries of the hip in rowers. Clin Orthop Relat Res 2013;471:2517-22.

7 Kuhns BD, Weber AE, Levy DM, et al. The natural history of femoroacetabular impingement. Front Surg 2015;2:58.

8 Sogbein OA, Shah A, Kay J, et al. Predictors of outcomes after hip arthroscopic surgery for femoroacetabular impingement: a systematic review. Orthop J Sports Med 2019;7:232596711984898.

9 Fernquest S, Arnold C, Palmer A, et al. Osseous impingement occurs early in flexion in cam-type femoroacetabular impingement: a 4D CT model. Bone Joint J 2017;99-B:41-8.

10 Moley PJ, Gribbin CK, Vargas E, et al. Co-diagnoses of spondylolysis and femoroacetabular impingement: a case series of adolescent athletes. J Hip Preserv Surg 2018;5:393-8.

11 Martinez-Valdes E, Wilson F, Fleming N, et al. Rowers with a recent history of low back pain engage different regions of the lumbar erector spinae during rowing. J Sci Med Sport 2019;22:1206-12.

12 Thorborg K, Hölmich P, Christensen R, et al. The Copenhagen hip and groin outcome score (HAGOS): development and validation according to the COSMIN checklist. Br J Sports Med 2011;45:478-91.

13 Fairbank JC, Pynsent PB. The Oswestry disability index. Spine 2000;25:2940-53.

14 Byrd JWT. Evaluation of the hip: history and physical examination. $N$ Am J Sports Phys Ther 2007;2:231-40.

15 Reiman MP, Thorborg K. Clinical examination and physical assessment of hip joint-related pain in athletes. Int J Sports Phys Ther 2014;9:737-55.

16 Palmer A, Fernquest S, Gimpel M, et al. Physical activity during adolescence and the development of CAM morphology: a cross-sectional cohort study of 210 individuals. Br J Sports Med 2018;52:601-10.

17 Agricola R, Waarsing JH, Thomas GE, et al. Cam impingement: defining the presence of a CAM deformity by the alpha angle: data from the check cohort and Chingford cohort. Osteoarthritis Cartilage 2014;22:218-25.

18 Sveen SA, Martin K, Alhaug E, et al. CAM-type femoroacetabular impingement in male elite junior cross-country skiers and non- 
athlete controls: a cross-sectional MRI study. BMJ Open Sport Exerc Med 2019;5: 000530.

19 Rajasekaran S, Kanna RM, Senthil N, et al. Genetic susceptibility of lumbar degenerative disc disease in young Indian adults. Eur Spine J 2015;24:1969-75.

20 Zobel BB, Vadalà G, Del Vescovo R, et al. T1 $\rho$ magnetic resonance imaging quantification of early lumbar intervertebral disc degeneration in healthy young adults. Spine 2012;37:1224-30.

21 Bittersohl B, Benedikter C, Franz A, et al. Elite Rowers demonstrate consistent patterns of hip cartilage damage compared with matched controls: a T2* mapping study. Clin Orthop Relat Res 2019;477:1007-18.

22 Lerebours F, Robertson W, Neri B, et al. Prevalence of CamType morphology in elite ice hockey players. Am J Sports Med 2016;44:1024-30.

23 Mosler AB, Crossley KM, Waarsing JH, et al. Ethnic differences in bony hip morphology in a cohort of 445 professional male soccer players. Am J Sports Med 2016;44:2967-74.

24 Larson CM, Sikka RS, Sardelli MC, et al. Increasing alpha angle is predictive of athletic-related "hip" and "groin" pain in collegiate National Football League prospects. Arthroscopy 2013;29:405-10.

25 Gerhardt MB, Romero AA, Silvers HJ, et al. The prevalence of radiographic hip abnormalities in elite soccer players. Am J Sports Med 2012;40:584-8.

26 Knapik DM, Gaudiani MA, Camilleri BE, et al. Reported prevalence of radiographic CAM deformity based on sport: a systematic review of the current literature. Orthop J Sports Med 2019;7:232596711983087.

27 Heerey JJ, Kemp JL, Mosler AB, et al. What is the prevalence of hip intra-articular pathologies and osteoarthritis in active athletes with hip and groin pain compared with those without? A systematic review and meta-analysis. Sports Med 2019;49:951-72.

28 Foss IS, Holme I, Bahr R. The prevalence of low back pain among former elite cross-country skiers, rowers, orienteerers, and nonathletes: a 10-year cohort study. Am J Sports Med 2012;40:2610-6.

29 Rumball JS, Lebrun CM, Di Ciacca SR, et al. Rowing injuries. Sports Med 2005;35:537-55.
30 Clay H, Mansell J, Tierney R. Association between ROWING injuries and the functional movement SCREEN ${ }^{\top M}$ in female collegiate division I ROWERS. Int $J$ Sports Phys Ther 2016;11:345-9.

$31 \mathrm{Ng} \mathrm{L}$, Perich D, Burnett A, et al. Self-Reported prevalence, pain intensity and risk factors of low back pain in adolescent rowers. $J$ Sci Med Sport 2014;17:266-70.

32 InBurton MR, Mesfin FB. Isthmic spondylolisthesis. Treasure Island, FL, 2019.

33 Buckeridge EM, Bull AMJ, McGregor AH. Biomechanical determinants of elite rowing technique and performance. Scand $J$ Med Sci Sports 2015;25:e176-83.

34 Holt PJE, Bull AMJ, Cashman PMM, et al. Kinematics of spinal motion during prolonged rowing. Int J Sports Med 2003;24:597-602.

35 McGregor A, Anderton L, Gedroyc W. The assessment of intersegmental motion and pelvic tilt in elite oarsmen. Med Sci Sports Exerc 2002;34:1143-9.

36 Wilson F, Gissane C, McGregor A. Ergometer training volume and previous injury predict back pain in rowing; strategies for injury prevention and rehabilitation. Br J Sports Med 2014;48:1534-7.

37 Buckeridge EM, Bull AMJ, McGregor AH. Foot force production and asymmetries in elite rowers. Sports Biomech 2014;13:47-61.

38 Zhang J, Zhao F, Wang F-L, et al. Identification of lumbar disc disease hallmarks: a large cross-sectional study. Springerplus 2016;5:1973.

39 Röling MA, Mathijssen NMC, Bloem RM. Incidence of symptomatic femoroacetabular impingement in the general population: a prospective registration study. J Hip Preserv Surg 2016;3:203-7.

40 Delitto A, George SZ, Van Dillen L, et al. Low back pain. J Orthop Sports Phys Ther 2012;42:A1-57.

41 Donnally III CJ, Hanna AVM. Lumbar Degenerative Disk Disease. Treasure Isl [Internet], 2021. Available: https://www.ncbi.nlm.nih.gov/ books/NBK448134/

42 Griffin DR, Dickenson EJ, O'Donnell J, et al. The Warwick agreement on femoroacetabular impingement syndrome (FAI syndrome): an international consensus statement. Br J Sports Med 2016;50:1169-76. 